\title{
The ratio principle holds over a million-to-one range of illumination
}

\author{
ALAN JACOBSEN \\ Boeing Commercial Airplane Company, Seattle, Washington \\ and \\ ALAN GILCHRIST \\ Institute for Cognitive Studies, Rutgers University, Newark, New Jersey
}

\begin{abstract}
A pattern of five gray squares ranging from white to black was presented to observers at four levels of illumination, spanning a range of six $\log$ units. This replicated an earlier experiment by Jameson and Hurvich (1961) in which a 1.1-log-unit range was used. Three measures of perception were used: (1) a "lightness" measure consisting of a square of variable luminance surrounded by a bright white field (after Jameson \& Hurvich), (2) a Munsell chart, and (3) a "brightness" measure consisting of a square of variable luminance surrounded by complete darkness (after Heinemann, 1955; Leibowitz, Mote, \& Thurlow, 1953; and Leibowitz, Myers, \& Chinetti, 1955). The first two measures yielded the same results-a very high degree of constancy over the entire range. No diverging or negative functions were found. The brightness measure yielded almost no constancy, but did yield approximate luminance matching. It is argued that these results, together with those of three other published studies, indicate that the concept of intensity dependence is not valid. It is also suggested that the term "brightness constancy" is a misnomer, since brightness varies with illumination.
\end{abstract}

In 1948, Wallach published a now classic set of experiments in which he showed that the perceived shade of gray of a surface depends not on its luminance (the absolute amount of light it reflects), but on the ratio between its luminance and the luminance of the surrounding region. He showed that a disk of constant luminance could be made to appear as any shade between white and black simply by varying the luminance of a surrounding annulus. In addition, he offered quantitative results showing that when observers are presented with two such disk/ annulus displays on opposite sides of a darkened room, and asked to adjust the luminance of one disk (the comparison) until it appears the same shade of gray as the other (standard) disk, they will actually set the luminance of the comparison disk to almost the same ratio with the luminance of its annulus as that of the standard disk in relation to its annulus, even though this may require that the luminance of the comparison disk be set as much as eight times that of the standard.

These experiments were important because they offered a simple explanation of lightness constancy under changing illumination that bypassed Helmholtz's (1867/1962) less operational cognitive account. They further suggested the radical possibility that the visual system might have no need at all for absolute luminance levels-that lightness perception might be determined rather simply by relative amounts of light.

Correspondence may be addressed to A. Gilchrist at the Department of Psychology, Rutgers University, Newark, NJ 07102.
This possibility, however, seemed to be diminished some time later in an experiment by Jameson and Hurvich (1961). In a further test of the ratio idea, they rearprojected an achromatic pattern of five squares, ranging in appearance from white to black, on a gray background. This pattern was presented to observers at three levels of projector intensity, simulating a 12 -fold illumination range. At each of the three "illumination" levels, observers were asked to match the lightness (or brightness) of each of the five squares by adjusting the luminance of a comparison square (presented in a separate chamber) that was surrounded by a large white region that was at all times brighter than the variable comparison square. This is a good method of measuring perceived lightness in that it produces a convincing experience of the range of surface grays from white to black, in a continuous, yet completely quantifiable, way. It is fundamentally equivalent to the Wallach disk-annulus pattern.

According to the Wallach principle, if luminance ratios are held constant, perceived lightness should also remain constant and, thus, Jameson and Hurvich's comparison square should be set at a constant luminance (for a given square) despite changes in the absolute luminance of the standard pattern.

But, instead, Jameson and Hurvich (1961) obtained remarkable departures from constancy, as shown in Figure 1. To make matters worse, departures from constancy went in both directions, depending on whether the standard square was light gray (including white) or dark gray (including black). Departures from constancy of a 


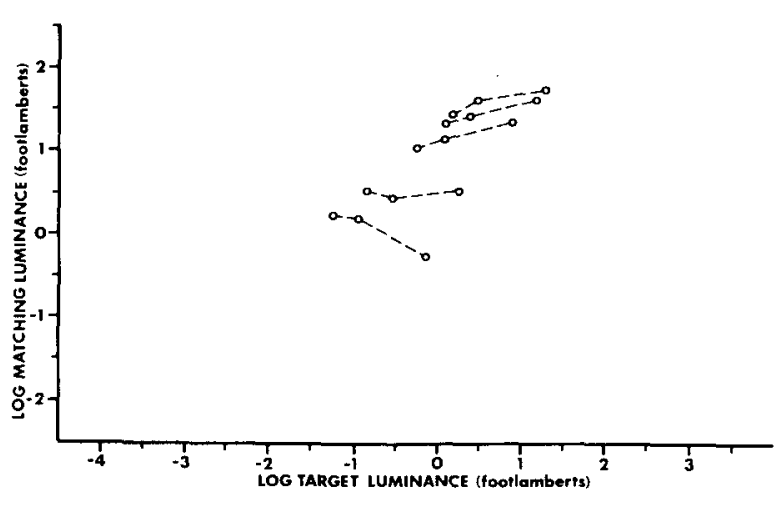

Figure 1. Data from Jameson and Hurvich (1961).

positive slope (higher luminance, higher lightness) have usually been found, to a greater or lesser extent, in such experiments (even slightly in the Wallach experiments), probably depending on the extent to which the observer was making a brightness, as opposed to a lightness, match. Thus, the positive slopes, by themselves, were not particularly noteworthy. But the negative slopes could not be readily explained outside the Jameson and Hurvich model. Jameson and Hurvich proposed that the perceived brightness (not distinguished by them from lightness) of a surface was the result of a balance between two opposing processes, an excitation, or whiteness, process, and an inhibition, or blackness, process. The net balance of these two processes, following a change in illumination, depended on a number of factors, they argued, including whether the target surface was brighter or darker than surrounding regions. Thus, diverging functions were not surprising. And constancy was to be expected only in those fortuitous cases in which the change in the inhibition process happened to just cancel out the change in the excitation process.

Jameson and Hurvich (1961) went on to argue that Wallach had failed to discover the diverging functions because he tested only a limited (8-to-1 at most) range of illumination. These arguments have become a standard part of the lightness literature. The Jameson and Hurvich experiment has been cited by almost every textbook of visual perception (Brown \& Deffenbacher, 1979; Day, 1969; Dember \& Warm, 1979; Forgus \& Melamed, 1976; Goldstein, 1980; Hochberg, 1978; Kaufman, 1974; Levine \& Shefner, 1981; Murch, 1973; Schiff, 1980; Schiffman, 1982), typically just following the description of Wallach's work, under the rationale that the Jameson and Hurvich results demonstrate the limitations on the ratio principle.

It is true that Wallach tested the ratio principle under no more than an 8-to-1 range of illumination. But Jameson and Hurvich (1961) expanded that range to only 12to-1! It seems unlikely that such a modest expansion of the range would produce results so different from those of Wallach, particularly in view of the fact that under everyday life conditions lightness perception remains reasonably veridical throughout an illumination range of at least 100 million to 1 (Brown \& Deffenbacher, 1979, p. 294; Dember \& Warm, 1979, p. 170; Goldstein, 1980, p. 137; Leibowitz, 1965, p. 7). If, under a mere 12-to-1 range, the functions diverge as much as Jameson and Hurvich report, what could they possibly look like under a range of 1 million to 1 ?

The theoretical stakes are significant, for if the ratio principle does not apply across a broad range of illumination, it loses much of its theoretical interest. More than that, the Jameson and Hurvich (1961) results challenge not only the ratio principle, but also the very concept of lightness constancy itself, which has served as the factual basis that theories of lightness perception have attempted to explain.

Since agreement on the facts of lightness perception is an obvious prerequisite to an adequate theory, it is important to try to resolve this issue, which divides such respected investigators. In seeking this resolution, we have pursued two goals: first, to conduct a very careful study of lightness constancy over a large, ecologically valid range of illumination, and second, to include in the same study all of the principle response measures that have previously been used in separate studies, producing in many cases different findings.

We used three methods of measurement that have seen general use. They are:

1. Munsell chart: A series of gray paper samples from white to black on a uniform background is presented, and the observer selects the sample that matches a target surface in the standard display, as in Burzlaff (1931). This method is simple but has been criticized on the grounds that constancy results are artificially favored by the simultaneous presentation of the entire range of gray shades.

2. Lightness measure: A square of variable luminance is presented on a bright white background. This is the method used in the Jameson and Hurvich (1961) study, as well as in Wallach's (1948) classic study. We hypothesized that it would produce results equivalent to those of the Munsell chart.

3. Brightness measure: A square of variable luminance is presented on a totally dark background. This method has been used by Heinemann (1955), Leibowitz, Mote, and Thurlow (1953), and Leibowitz, Myers, and Chinetti (1955). It has been criticized by Rock (1975, p. 515) on the grounds that it produces a mode of color appearance (film or aperture mode; see Beck, 1972; Katz, 1911/1935) that is qualitatively different from that of surface colors. For instance, it is virtually impossible to match the lightness of a charcoal gray surface using this method, since the square of light on the dark background never appears as an opaque gray surface, no matter how low its luminance is set; it always appears as a glowing source of light, albeit a very dim source. We hypothesized that this method could produce a measure of brightness (perceived luminance) but not lightness (perceived reflectance). Our distinction here follows that of Evans (1948, pp. 158, 159). 


\section{METHOD}

\section{Observers}

A total of 9 naive undergraduate volunteers served, 3 in each condition.

\section{Apparatus}

Five squares $\left(4.8 \mathrm{~cm}, 3^{\circ}\right)$ of achromatic Munsell paper (reflectances of $90,50.7,30.1,9$, and 3.1) were arranged in a cross pattern on a $19.3-\mathrm{cm}\left(12^{\circ}\right)$ square background of $20 \%$ reflectance. This test display (which replicated that of Jameson \& Hurvich, 1961, except that they used rear projection) was mounted vertically and illuminated with various combinations of light bulbs. At the lowest level, a $24-\mathrm{W}$ bulb was used at approximately $8 \mathrm{~V}$. At the second level, a 25-W bulb was used; at the third level, a 100-W bulb was used; and at the highest level, one $500-\mathrm{W}$ bulb and one $1,500-\mathrm{W}$ quartz-halogen flood light were used. All of these lights were located at a distance of approximately $46 \mathrm{~cm}$ from the display. Four levels of illumination were produced; $.00153,1.26,15.93$, and $1,602 \mathrm{fc}$. The test display was located $91.65 \mathrm{~cm}$ from the eye of the observer, who viewed it in one of two ways. In a binocular condition, the observer viewed the display alternately (by turning the head), with one of the three matching chambers, which were mounted on a rolling table so that any one of the three could be easily placed at the desired location, directly ahead of the observer and $90^{\circ}$ to the right of the test display. In the haploscopic conditions, the observer's face was placed against a $30-\mathrm{cm}$-square board that contained two viewing tubes, $7.5 \mathrm{~cm}$ long and $6 \mathrm{~cm}$ in diameter, mounted $4 \mathrm{~cm}$ apart ( $10 \mathrm{~cm}$ center-to-center), facing the matching chamber. The right-hand tube opened directly into the aperture of whichever matching chamber was in place. A mirror was mounted diagonally behind the left-hand tube so that the test display was seen with the left eye only. This allowed the left eye to be kept at a different level of adaptation while the right eye was exposed to the higher levels of illumination in the matching chambers. To prevent binocular overlap, the left-eye image of the test display was separated by $65^{\circ}$ of darkness from the right-eye image of the matching chamber.

To make lightness matches, the observer looked through a 7-cmhigh $\times 15-\mathrm{cm}$-wide aperture into the near end of a rectangular chamber ( $45 \mathrm{~cm}$ wide $\times 45 \mathrm{~cm}$ high $\times 70 \mathrm{~cm}$ long) that was painted white (reflectance $=85 \%$ ) and illuminated by two 40 -W light bulbs (located just above and below the inside of the viewing aperture). This gave the wall at the far end a luminance of $46 \mathrm{fl}$. A rectangular aperture $(1.3 \mathrm{~cm}$ wide $\times 1.8 \mathrm{~cm}$ high $)$ in the center of this wall served as the matching target. It opened into a second, smaller chamber $(45 \mathrm{~cm} \times 45 \mathrm{~cm} \times 40 \mathrm{~cm}$ long), also painted white inside. A sliding panel on the left side of the apparatus allowed a variable amount of light (from two 150-W flood lights) to pass through a round aperture $(15 \mathrm{~cm}$ in diameter) into the rear chamber. By moving a metal rod attached to the sliding panel, the observer could cause the matching target (which did not appear to be a hole) to appear as any shade of gray from black to white (and on to luminosity, if necessary).

The brightness apparatus was identical in all crucial dimensions except that the near chámber (into which the observer looked) was painted black (reflectance $=3.5 \%$ ) and was not illuminated.

The chamber containing the Munsell chart was $32 \mathrm{~cm}$ high $\times$ $33 \mathrm{~cm}$ wide $\times 42 \mathrm{~cm}$ long. The chamber was painted white inside and was illuminated with a single $100-W$ light bulb. A Munsell chart consisting of 16 achromatic chips $(2.3 \mathrm{~cm}$ high $\times 1.6 \mathrm{~cm}$ wide, with $0.87 \mathrm{~cm}$ between chips) arranged in a single horizontal row on a piece of white (reflectance $=85 \%$ ) cardboard $(24.3 \mathrm{~cm}$ high $\times 64.3 \mathrm{~cm}$ wide) was affixed to the chamber's far wall, which stood in $51.1 \mathrm{fc}$ of illumination.

\section{Design}

Condition 1: Binocular. The lowest level of illumination was not used in this condition. The observers made a block of 15 matches ( 5 target squares $\times 3$ illumination levels, completely randomized) with one matching chamber, followed by a similar block of 15 matches with each of the other two matching chambers. The order of matching chambers was randomized.

Condition 2: Haploscopic. This condition served as an exact replication of Jameson and Hurvich's (1961) study, except for our use of a paper display. The observers first made all matches with the lowest level of illumination. The five target squares were matched (in random order) using one matching chamber, and this was then repeated for the other two chambers. The order of matching chambers was randomized. Following this, matches were made for the three higher levels of illumination, using the same design as in Condition 1, except that the haploscopic method was maintained.

Condition 3: Haploscopic. Observers first made all matches with the lowest level of illumination, just as in Condition 2. This same design was then repeated for each of the higher levels of illumination, in random order, using the haploscopic method throughout.

\section{Instructions}

The observers were read the following set of instructions while they were seated in the observer chair prior to making any matches.

In this experiment you will be presented with a display pattern that consists of five different target areas. Your task will be use these chambers to make a match to each of these targets.

Each of the three matching chambers was then presented so that the observers could familiarize themselves with the matching procedure.

\section{Munsell selection chamber:}

Choose the chip from the chart that best matches the shade of gray of the target.

\section{Lightness production chamber:}

By moving this rod in and out you can change the shade of gray of the small rectangular area. You should set the rod so that this small area matches the shade of gray of the target.

\section{Brightness chamber:}

By moving this rod in and out you can change the brightness of the small rectangular area. You should set the rod so that this small area matches the brightness of the target.

Observers in viewing Condition 1 were then told:

By looking into this aperture on your left, you can see the targets. After you are told which target to match, turn your head and look into this aperture to make your match. You may look back and forth as many times as you feel it necessary to achieve a good match. You will be making a total of 15 matches with each of the three matching chambers.

\section{Observers in viewing Conditions 2 and 3 were told:}

By looking into this aperture, you will be able to see the target squares with your left eye and the matching chamber with your right eye. When you are told which target to match, begin making your match. You may take as long as you feel it necessary to achieve a good match. You will be making a total of 20 matches with each of the three matching chambers.

All observers were then asked if they had any questions. As the subsequent matching chambers were presented, the observers were 
Table 1

Average Matching Luminances

\begin{tabular}{|c|c|c|c|c|c|c|c|c|c|c|}
\hline \multirow{2}{*}{$\begin{array}{l}\text { Target } \\
\text { Square }\end{array}$} & \multirow{2}{*}{$\begin{array}{l}\text { Target } \\
\text { Lum. }\end{array}$} & \multicolumn{3}{|c|}{ Lightness Match } & \multicolumn{3}{|c|}{ Munsell Match } & \multicolumn{3}{|c|}{ Brightness Match } \\
\hline & & Bin & Hap2 & $\overline{\text { Hap3 }}$ & Bin & Hap2 & Hap3 & Bin & Hap2 & Hap3 \\
\hline $\begin{array}{l}\text { Center } \\
\text { White } \\
R=90 \%\end{array}$ & $\begin{array}{r}-2.77 \\
0.15 \\
1.25 \\
3.25\end{array}$ & $\begin{array}{l}1.76 \\
1.77 \\
1.85\end{array}$ & $\begin{array}{l}1.58 \\
1.65 \\
1.72 \\
1.79\end{array}$ & $\begin{array}{l}1.57 \\
1.58 \\
1.74 \\
1.80\end{array}$ & $\begin{array}{l}1.64 \\
1.67 \\
1.67\end{array}$ & $\begin{array}{l}1.63 \\
1.64 \\
1.67 \\
1.67\end{array}$ & $\begin{array}{l}1.58 \\
1.67 \\
1.67 \\
1.67\end{array}$ & $\begin{array}{r}-0.21 \\
0.28 \\
2.14\end{array}$ & $\begin{array}{c}-1.73 \\
-0.41 \\
1.13 \\
* *\end{array}$ & $\begin{array}{c}-2.05 \\
0.18 \\
0.58 \\
* *\end{array}$ \\
\hline $\begin{array}{l}\text { Right } \\
\text { L. Gray } \\
R=50.7 \%\end{array}$ & $\begin{array}{r}-3.02 \\
-0.10 \\
1.00 \\
3.00\end{array}$ & $\begin{array}{l}1.46 \\
1.50 \\
1.66\end{array}$ & $\begin{array}{l}1.39 \\
1.46 \\
1.52 \\
1.67\end{array}$ & $\begin{array}{l}1.38 \\
1.45 \\
1.48 \\
1.59\end{array}$ & $\begin{array}{l}1.42 \\
1.48 \\
1.58\end{array}$ & $\begin{array}{l}1.42 \\
1.48 \\
1.57 \\
1.61\end{array}$ & $\begin{array}{l}1.44 \\
1.48 \\
1.51 \\
1.58\end{array}$ & $\begin{array}{l}0.29 \\
0.36 \\
4.70\end{array}$ & $\begin{array}{r}-2.30 \\
-0.99 \\
-0.02 \\
2.09\end{array}$ & $\begin{array}{r}* * * \\
-0.67 \\
0.02 \\
2.34\end{array}$ \\
\hline $\begin{array}{l}\text { Top } \\
\text { M. Gray } \\
R=30 \%\end{array}$ & $\begin{array}{r}-3.25 \\
-0.33 \\
0.77 \\
2.77\end{array}$ & $\begin{array}{l}1.29 \\
1.29 \\
1.59\end{array}$ & $\begin{array}{l}1.31 \\
1.36 \\
1.43 \\
1.53\end{array}$ & $\begin{array}{l}1.29 \\
1.30 \\
1.37 \\
1.53\end{array}$ & $\begin{array}{l}1.32 \\
1.38 \\
1.52\end{array}$ & $\begin{array}{l}1.27 \\
1.38 \\
1.44 \\
1.55\end{array}$ & $\begin{array}{l}1.27 \\
1.32 \\
1.32 \\
1.46\end{array}$ & $\begin{array}{l}0.35 \\
0.21 \\
2.56\end{array}$ & $\begin{array}{c}* * * \\
-1.08 \\
-0.61 \\
1.11\end{array}$ & $\begin{array}{r}* * * \\
-0.85 \\
-0.24 \\
2.15\end{array}$ \\
\hline $\begin{array}{l}\text { Left } \\
\text { D. Gray } \\
\text { R }=9 \%\end{array}$ & $\begin{array}{r}-3.77 \\
-0.85 \\
0.25 \\
2.25\end{array}$ & $\begin{array}{l}0.82 \\
1.05 \\
1.13\end{array}$ & $\begin{array}{l}1.03 \\
1.10 \\
1.18 \\
1.30\end{array}$ & $\begin{array}{l}0.69 \\
0.96 \\
1.11 \\
1.30\end{array}$ & $\begin{array}{l}0.72 \\
0.95 \\
1.14\end{array}$ & $\begin{array}{l}0.74 \\
0.79 \\
1.05 \\
1.19\end{array}$ & $\begin{array}{l}0.67 \\
0.72 \\
0.79 \\
1.01\end{array}$ & $\begin{array}{l}0.17 \\
0.06 \\
0.38\end{array}$ & \begin{tabular}{r}
\multicolumn{1}{c}{$* * *$} \\
-1.23 \\
-0.73 \\
0.57
\end{tabular} & $\begin{array}{r}* * * \\
-1.29 \\
-0.60 \\
1.80\end{array}$ \\
\hline $\begin{array}{l}\text { Bottom } \\
\text { Black } \\
\mathrm{R}=3.13 \%\end{array}$ & $\begin{array}{r}-4.23 \\
-1.31 \\
-0.21 \\
1.79\end{array}$ & $\begin{array}{l}0.40 \\
0.53 \\
0.66\end{array}$ & $\begin{array}{l}0.54 \\
0.60 \\
0.58 \\
0.98\end{array}$ & $\begin{array}{l}0.20 \\
0.43 \\
0.71 \\
0.81\end{array}$ & $\begin{array}{l}0.28 \\
0.53 \\
0.59\end{array}$ & $\begin{array}{l}0.31 \\
0.31 \\
0.38 \\
0.61\end{array}$ & $\begin{array}{l}0.31 \\
0.31 \\
0.31 \\
0.44\end{array}$ & $\begin{array}{l}0.03 \\
0.26 \\
1.90\end{array}$ & $\begin{array}{c}* * * \\
-1.42 \\
-0.71 \\
0.14\end{array}$ & $\begin{array}{c}* * * \\
-1.46 \\
-0.66 \\
1.51\end{array}$ \\
\hline
\end{tabular}

Note-All luminances given in log footlamberts. Bin = binocular; Hap2 = haploscopic, Condition 2; Hap3 $=$ haploscopic, Condition 3. ${ }^{* *}$ Apparatus did not permit a bright enough setting for match. ${ }^{* * *}$ Observers were unable to make a satisfactory match due to the phenomenal difference between decrements (the target square) and increments (the matching square).

quickly reminded about how to make matches. In between each match, the rod on the lightness and brightness chambers was pushed in or pulled out all the way in random order by the experimenter.

\section{RESULTS}

The average matching luminances for the five target squares, three matching apparati, and three conditions are given in Table 1. Our lightness data from Condition 3 (haploscopic viewing) are compared with Jameson and Hurvich's (1961) lightness data in Figure 2, with our Munsell data in Figure 3, and with our brightness data in Figure 4.

\section{DISCUSSION}

The main implication of our results is that the ratio principle seems to be a general principle, not one that is limited to a small part of the illumination range or dependent on absolute intensity. The functions we obtained are so close to horizontal that it seems possible that the residual positive slope could be eliminated by the use of extremely careful procedures, such as dark-adapting observers before every single match.

Our results are supported by a series of other studies. Flock and Noguchi (1970) replicated the Jameson and Hurvich experiment using seven test squares and white, gray, and black backgrounds. These and other departures were introduced to maximize the probability of obtaining negative functions. None were obtained. Noguchi and
Masuda (1971) and Haimson (1974) also failed to find negative slopes in very close replications of Jameson and Hurvich's (1961) experiment. Arend and Goldstein (in press), using state-of-the-art computer graphics, reported near-perfect lightness constancy, but found that brightness judgments were harder and far from constant, going in the direction reported here (luminance matching).

There is also an early experiment by Burzlaff (1931, cited in Woodworth \& Schlosberg, 1954) that is, in most essential respects, equivalent to that of Jameson and Hurvich (1961). Burzlaff presented two arrays of achromatic papers, one in dim illumination and one in bright illumination, and asked observers to select a sample from the

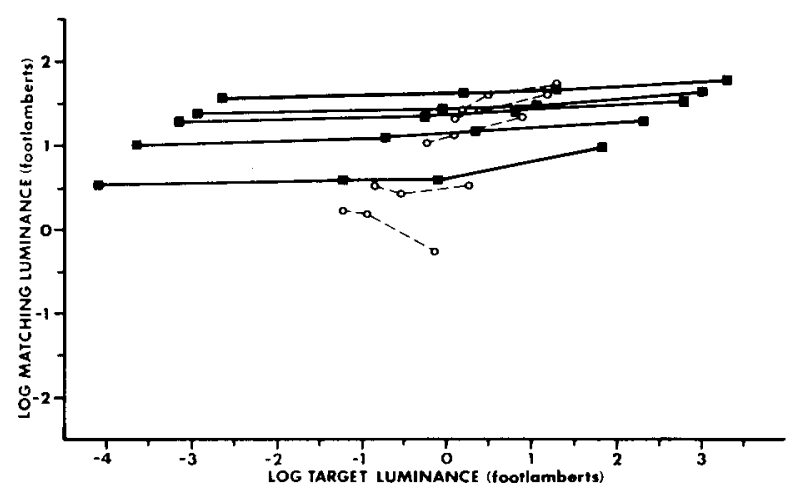

Figure 2. Lightness data from present experiment, Condition 3, compared with data from Jameson and Hurvich (1961). 
array in dim illumination that matched each of the samples in bright illumination. He obtained a set of approximately parallel functions of a slightly positive slope and no negative functions at all.

The illumination ranges used in the above studies were as follows: Flock and Noguchi, 18:1; Noguchi and Masuda, 16:1; Haimson, 10,000:1; Arend and Goldstein, 19:1; Burzlaff, 20:1.

Other research, using very careful techniques, has yielded almost perfect ratio results with no systematic departures from ratio functions at all. Whittle and Challands (1969) have produced essentially perfect ratio results using a haploscopic technique in which the two targets being compared appear to stand on the same background. Walraven (1976) has extended this finding to chromatic color.

\section{Related Findings}

There exist in the literature three other studies that, although not replications, bear a general approximation to the Jameson and Hurvich (1961) results and have been interpreted by Jameson and Hurvich and others as providing further evidence of diverging functions.

1. S. S. Stevens and J. C. Stevens (1960) presented a graph showing a set of diverging functions they described as a "generalized set of functions showing the brightness of a disk seen in the presence of a surround" (p. VIII15a). This graph has been widely understood as a set of empirical data points. A careful look at the Stevens and Stevens report shows, however, that the graph is a theoretical construct, extrapolated from some fractionation studies, showing how Stevens and Stevens would have expected the data to come out if the complete study had been conducted. This has been confirmed by J. C. Stevens (personal communication, August 3, 1987).

2. A study by Bartleson and Breneman (1967) produced a set of curves that might be described as diverging, although each curve itself has a sharp inverted-U function that is quite dissimilar to those of S. S. Stevens and J. C. Stevens (1960). In addition, Bartleson and Breneman increased the level of illumination on a black and white photograph of a complex scene, leaving the level of illumination of the scene captured by the photograph

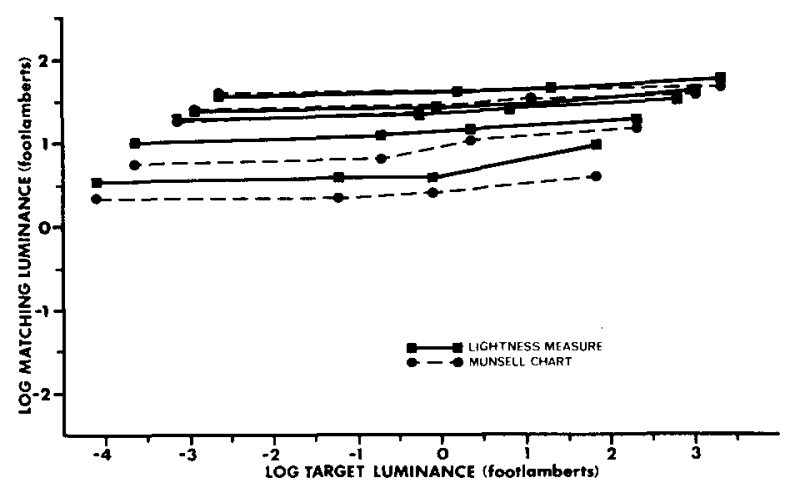

Figure 3. Lightness data (present experiment), Condition 3, compared with Munsell chart data, Condition 3.

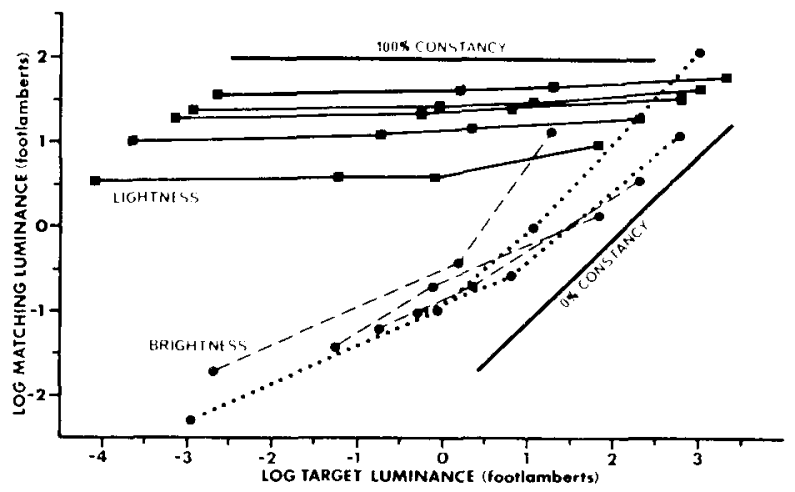

Figure 4. Lightness data (present experiment), Condition 3, compared with brightness data, Condition 3 .

unchanged. These factors make it very difficult to speculate on what their data mean.

3. The experiment on which Jameson and Hurvich $(1961,1964)$ relied most heavily for collaborative evidence is a very early study by Hess and Pretori (1894/1970). This study, which could be considered an early precursor of the Wallach study, not only employed a wide range of illumination, but also varied the range of the surround: center ratio itself from 5,000:1 to 1:256. We have also replicated this study (Jacobsen \& Gilchrist, 1988), finding major artifacts that dramatically distort the data. We report this work in a companion paper.

At this point, the weight of the evidence strongly suggests that the claim that dark grays appear blacker as the illumination increases (along with the concept of diverging functions) should be rejected. The negative slope found by Jameson and Hurvich (1961) is essentially unreplicable.

This conclusion, if accepted, carries important implications for what we have previously (Gilchrist, Delman, \& Jacobsen, 1983; Gilchrist \& Jacobsen, 1984) called the photometer metaphor, the widely shared assumption that lightness processing begins with an initial point-by-point response to absolute luminance values across the visual field. We suggest that the "intensity-dependence" idea implicit in the diverging-functions concept has, in our view, been the most important empirical finding that could not be equally well explained by a thoroughly relational approach in which absolute luminance values need play no role whatsoever.

We suggest that although such contrast theories as those of Jameson and Hurvich (1964) and Cornsweet (1970) appear consistent with a relational approach, they actually undermine it, since the nature of the relational process (in their terms, the net balance between the opponent processes) ultimately depends upon the absolute luminance levels involved. Hence the term "intensity dependence." As Koffka said in 1935, "the term contrast is no more than a name which we prefer to avoid since it implies an explanation not in terms of gradient but in terms of absolute amounts of light"' (p. 245).

Lightness measure versus Munsell chart. As can be observed in Figure 3, the data we obtained with the Mun- 
sell chart were essentially equivalent to those obtained with the lightness measure. This is nice to know because each method has its advantages. The Munsell chart is convenient, while the lightness measure provides a continuous scale.

Lightness versus brightness. Our results show that observers can respond to two quite different variables of the stimulus at the same time. Our lightness measure indicates that observers experience the reflectance of the target as remaining the same even as the brightness measure indicates that the luminance of the target is experienced as increasing. Thus, our results not only provide additional support for this distinction, which has not been universally accepted, but also clarify the concrete conditions necessary for measuring each.

The fact that our brightness measure produced a positive slope of almost 1 supports the claim made earlier by Gilchrist (1977) that the term "brightness constancy"' is a misnomer. Brightness, unless it is used as a synonym for lightness, is not constant under a change of illumination.

\section{What Changes When Ilumination is Increased?}

We agree that things look different under brighter illumination. First, everything looks brighter. Second, more shades of gray can be distinguished. Put more technically, the number of just noticeable differences (jnds) between white and black must be greater under higher illumination. For instance, we know that the illumination can be reduced to the point at which no difference less than that between adjacent white and black surfaces can be perceived; any smaller difference would be too little to perceive. In this case, there is only one jnd between black and white. Yet, under bright illumination, many shades of gray are discriminable (Hering, 1874/1964). But these changes in discriminability are independent of perceived lightness, which seems to remain constant.

\section{REFERENCES}

Arend, L. E., \& Goldstein, R. (in press). Simultaneous constancy, lightness and brightness. Journal of the Optical Society of America. Bartleson, C. J., \& Breneman, E. J. (1967). Brightness perception in complex fields. Journal of the Optical Society of America, 57, 95.

BECK, J. (1972). Surface color perception. Ithaca: Cornell University Press.

Brown, E. L., \& Deffenbacher, K. (1979). Perception and the senses. New York: Oxford University Press.

Cornsweet, T. N. (1970). Visual perception. New York: Academic Press.

DAY, R. H. (1969). Human perception. New York: Wiley.

Dember, W. N., \& WARM, J. S. (1979). Psychology of perception. New York: Holt, Rinehart \& Winston.

Evans, R. M. (1948). An introduction to color. New York: Wiley. Flock, H. R., \& NoGUCHI, K. (1970). An experimental test of Jameson and Hurvich's theory of brightness contrast. Perception \& Psychophysics, 8, 129-136.

Forgus, R. H., \& Melamed, L. E. (1976). Perception: A cognitivestage approach. New York: McGraw-Hill.

GiLchrist, A. L. (1977). Color constancy. In B. Wolman (Ed.), The international encyclopedia of neurology, psychiatry, psychoanalysis, and psychology. New York: Van Nostrand.

Gilchrist, A. L., Delman, S., \& Jacobsen, A. (1983). The classifi- cation and integration of edges as critical to the perception of reflectance and illumination. Perception \& Psychophysics, 33, 425-436.

Gilchrist, A., \& JACOBSEN, A. (1984). Perception of lightness and illumination in a world of one reflectance. Perception, 9, 936-944.

Goldstein, E. B. (1980). Sensation and perception. Belmont, CA: Wadsworth.

Haimson, B. R. (1974). The response criterion, the stimulus configuration, and the relationship between brightness contrast and brightness constancy. Perception \& Psychophysics, 16, 347-354.

HeinemanN, E. G. (1955). Simultaneous brightness induction as a function of inducing and test-field luminances. Journal of Experimental Psychology, 50, 89-96.

HeLmholtz, H. von (I962). Helmholtz's treatise on physical optics (J. P. Southall et al., Eds. and Trans.). New York: Dover. (Original work published 1867)

Hering, E. (1964). Outlines of a theory of the light sense (L. M. Hurvich \& D. Jameson, Trans.). Cambridge, MA: Harvard University Press. (Original work published 1874)

Hess, C., \& Pretori, H. (1970). Quantitative investigation of the lawfulness of simultaneous brightness contrast $(H$. R. Flock \& J. H. Tenney, Trans.). Perceptual \& Motor Skills, 31, 947-969. (Original work published 1894)

HochberG, J. E. (1978). Perception. Englewood Cliffs, NJ: Prentice-Hall.

JaCOBSEn, A., \& Gilchrist, A. (1988). Hess and Pretori revisited: Resolution of some old contradictions. Perception \& Psychophysics, 43, $7-14$.

JAMEson, D., \& Hurvich, L. M. (1961). The complexities of perceived brightness. Science, 133, 174-179.

JAMESON, D., \& HuRVICH, L. M. (1964). Theory of brightness and color contrast in human vision. Vision Research, 4, 135-154.

KATZ, D. (1935). The world of color (2nd ed., R. B. MacLeod \& C. W Fox, Trans.). London: Kegan Paul, Trench, \& Trubner. (Original work published 1911)

Kaufman, L. (1974). Sight and mind. New York: Oxford University Press.

KoFFKa, K. (1935). Principles of Gestalt psychology. New York: Harcourt, Brace, \& World.

LeIBOWTTZ, H. W. (1965). Visual perception. New York: Macmillan. Leibowitz, H., Mote, F. A., \& ThuRLow, W. R. (1953). Simultaneous contrast as a function of separation between test and inducing fields. Journal of Experimental Psychology, 46, 453-456.

Leibowitz, H., Myers, N. A., \& ChinetTi, P. (1955). The role of simultaneous contrast in brightness constancy. Journal of Experimental Psychology, 50, 15-18.

Levine, M. W., \& ShefNer, J. M. (1981). Fundamentals of sensation and perception. Reading: Addison-Wesley.

Murch, G. M. (1973). Visual and auditory perception. New York: Bobbs-Merrill.

Noguchi, K., \& MAsuda, N. (1971). Brightness changes in a complex field with changing illumination: A re-examination of Jameson and Hurvich's study of brightness constancy. Japanese Psychological Research, 13, 60-69.

Rock, I. (1975). An introduction to perception. New York: Macmillan. SchIFF, W. (1980). Perception: An applied approach. Boston: Houghton Mifflin.

SCHIFFMAN, H. R. (1982). Sensation and perception: An integrated approach. New York: Wiley.

Stevens, S. S., \& Stevens, J. C. (1960). The dynamics of visual brightness (Psychological Project Report No. PPR-246, 1). Cambridge, MA: Harvard University.

WALLACH, H. (1948). Brightness constancy and the nature of achromatic colors. Journal of Experimental Psychology, 38, 310-324.

Walraven, J. (1976). Discounting the background: The missing link in the explanation of chromatic induction. Vision Research, 16, 289-296.

Whittle, P.. \& Challands, P. D. C. (1969). The effect of background luminance on the brightness of flashes. Vision Research, 9, 1095-1110. WoODWORTH, R. S., \& SCHLOSBERG, H. (1954). Experimental psychology. New York: Holt.

(Manuscript received April 22, 1987; revision accepted for publication July 17,1987 .) 